\title{
Evaluación, criterios de elección y uso de los libros de texto de química: los profesores de Confresa / MT toman la palabra
}

\author{
Antônio Carlos Barros Resplande \\ carlos_caca10@hotmail.com \\ https://orcid.org/ 0000-0003-0467-5462 \\ Instituto Federal de Mato Grosso (IFMT) \\ Confresa/MT, Brasil. \\ Marcelo Franco Leão \\ marcelo.leao@ifmt.edu.br \\ https://orcid.org/ 0000-0002-9184-916X \\ Instituto Federal de Mato Grosso (IFMT) \\ Confresa/MT, Brasil.
}

Recibido: 18/02/2021 Aceptado: 22/10/2021

\section{Resumen}

El Libro Didáctico (LD) es un material pedagógico muy utilizado en las escuelas públicas brasileñas, sirve para dar soporte teórico a docentes y estudiantes de Educación Básica y que acaba influyendo en el desarrollo de las clases. El objetivo de esta investigación fue identificar los criterios de elección, la forma de uso en el aula y la evaluación de los docentes de secundaria que laboran en Confresa / MT en la LD de Química. Esta encuesta descriptiva y exploratoria se realizó en 2019 e involucró a 15 profesores de Química de las 09 escuelas que ofrecen la escuela secundaria en la ciudad. Se utilizó un cuestionario que contenía 15 preguntas abiertas. Los docentes investigados adoptan la contextualización y los contenidos abordados como criterios para la elección de la DA. En cuanto a la evaluación y uso de LD, además del considerable uso de este material didáctico, afirman que LD es un medio de investigación en la elaboración y uso en clases. El LD fue elegido mediante votación en la asamblea, en base al análisis cuidadoso de cada Guía de Libros Didácticos (GLD) que presentó al Programa Nacional de Libros y Material Didáctico (PNLD). El estudio también reveló que la DA es bien evaluada por la mayoría de los profesores, principalmente en lo que respecta a la contextualización y los lenguajes utilizados que consideran apropiados. Por tanto, la DA acaba influyendo en el desempeño de los profesores de Química y en consecuencia en la construcción del conocimiento escolar de los estudiantes. Palabras clave: Enseñanza de la Química. Libro Didáctico. Recurso Pedagógico.

\section{Avaliação, critérios de escolha e utilização dos livros didáticos de química: com a palavra os professores de Confresa/MT}

\section{Resumo}

O Livro Didático (LD) é um material pedagógico bastante utilizado nas escolas públicas brasileiras, serve para dar suporte teórico aos professores e alunos da Educação Básica e que acaba influenciando no desenvolvimento das aulas. O objetivo desta pesquisa foi identificar os critérios de escolha, a forma de utilização em sala de aula e a avaliação dos professores do Ensino Médio que atuam em Confresa/MT sobre os L) de Química. Esse levantamento descritivo e exploratório foi realizado em 2019 e envolveu 15 professores de Química das 09 
escolas que ofertam Ensino Médio no município. Foi utilizado um questionário contendo 15 questões abertas. Os professores investigados adotam a contextualização e os conteúdos abordados como critérios para a escolha do LD. Sobre a avaliação e utilização do LD, além de ser considerável o grande uso desse material didático, afirmam que o LD é um meio de pesquisa na elaboração e uso nas aulas. A escolha do LD ocorreu por meio de votação em assembleia, com base nas análises criteriosas de cada Guia do Livro Didático (GLD) que submeteu ao Programa Nacional do Livro e do Material Didático (PNLD). O estudo também revelou que o LD é bem avaliado pela maioria dos professores, principalmente referente a contextualização e as linguagens utilizadas que consideram apropriadas. Logo, o LD acaba por influenciar na atuação dos professores de Química e consequentemente na construção de conhecimentos escolares dos alunos.

Palavras chave: Ensino de Química. Livro Didático. Recurso Pedagógico.

\title{
Evaluation, criteria for choosing and using chemistry didactics books: teachers from Confresa / MT taking the floor
}

\begin{abstract}
The Didactic Book (DB) is a pedagogical material widely used in Brazilian public schools, it serves to give theoretical support to teachers and students of Basic Education and that ends up influencing the development of classes. The objective of this research was to identify the criteria of choice, the form of use in the classroom and the evaluation of high school teachers who work in Confresa / MT on the DB of Chemistry. This descriptive and exploratory survey was conducted in 2019 and involved 15 Chemistry teachers from the 09 schools that offer high school in the city. A questionnaire containing 15 open questions was used. The investigated teachers adopt the contextualization and the contents covered as criteria for choosing the DB. Regarding the evaluation and use of $\mathrm{DB}$, in addition to the considerable use of this didactic material, they state that DB is a means of research in the elaboration and use in classes. The DB was chosen through a vote in the assembly, based on the careful analysis of each Didactic Book Guide (DBG) that it submitted to the National Book and Didactic Material Program (NBDMP). The study also revealed that the DB is well evaluated by most teachers, mainly regarding contextualization and the languages used that they consider appropriate. Therefore, the DB ends up influencing the performance of Chemistry teachers and consequently in the construction of students' school knowledge.
\end{abstract}

Keywords: Chemistry Teaching. Didactic Book. Pedagogical Resource.

\section{Introdução}

O processo educativo está em constantes transformações, e com o Ensino de Química não é diferente. Além disso, o ato de ensinar envolve diversos elementos, tais como o planejamento pedagógico, os recursos e materiais didáticos, as estratégias de ensino e a avaliação da aprendizagem. Existem vários os recursos pedagógicos disponíveis para ensinar Química, dentre os mais utilizados podemos citar o Livro Didático (LD). 
No entanto, é preciso esclarecer que o LD não corresponde a uma versão fiel das diretrizes e programas curriculares oficiais, nem a uma versão fiel do conhecimento científico. Também não é utilizado por professores e alunos da mesma forma intentada pelos autores e editoras, como guia ou manual relativamente rígido e padronizado das atividades do processo educativo. Ele acaba por se configurar, na prática escolar, como um material de consulta e apoio pedagógico, que tem semelhanças como livros paradidáticos e outros tantos materiais de ensino, sendo também usado por professores que fazem do livro a sua própria aula.

As editoras fazem diversas alterações das coleções, tentando moldá-las à sua realidade escolar e as suas convicções mercadológicas, diante da visão que ela tem sobre a escola. Diante disso as editoras acabam por reconstruir o LD adotado, o que não agrada a todos, dado ao esforço complexo para tal reformulação sem o devido reconhecimento profissional, nem agrada aos editores e autores, pois consideram que essas adaptações usualmente introduzem erros e equívocos nas obras editadas.

Os LDs são importantes mecanismos de homogeneização de conceitos, conteúdos e abordagens de ensino (Lopes, 1992). A seleção dos LDs não deve excluir os professores como construtores ativos de saberes que desenvolvem essa importante competência profissional (Ramalho; Nuñez \& Gauthier, 2000).

A discussão sobre as ilustrações dos LDs tem como objetivo as verificações dos professores em reconhecer que geralmente na prática de seleção dos LDs, a qualidade gráfica prevalece ao conteúdo na questão de selecionar os LDs. Então as figuras, os gráficos e os diagramas dos LDs de Química são utilizados como ilustrações para facilitar a compreensão dos conteúdos teóricos, e, na atualidade, muitos deles procuram com as ilustrações contextualizar ou vincular à prática desses conhecimentos teóricos.

Sobre a contextualização, predomina instigar a curiosidade do aluno, despertar o desejo de aprender e mostrar que a Química é uma ciência extremamente vinculada à realidade (Peruzzo \& Canto, 1999).

Como é preconizado nos principais objetivos do Programa Nacional do Livro e do Material Didático (PNLD), se faz necessária a participação ativa e democrática do professor no processo de seleção dos mesmos. Segundo Fernandes (2009), o LD é um dos instrumentos do professor usado na organização dos trabalhos pedagógicos, sendo valiosas suas fontes de 
informação, podendo vir a despertar no aluno o gosto pela leitura, além de nortear o professor na condução do conteúdo a ser abordado em sala de aula.

Considerando a participação dos professores na escolha do LD e nas características do livro mais adotado, o estudo identificou avanços no processo de políticas públicas voltadas para o LD e indica possibilidades de superação de problemas identificados em estudos anteriores, principalmente no que diz respeito à 'ruptura da ruptura' (Santos, 1998), ou seja, à articulação entre ciência e senso comum.

Conforme defende Maroja (2007), a utilização de um novo tipo de abordagem usando LD, embora seja útil no processo educativo, ainda é pouco usada na prática docente, pois como se sabe o professor de Química ainda valoriza modelos curriculares que enfatizam fórmulas e a memorização.

A problemática desta pesquisa foi a necessidade de entender como foi escolhido os LDs da disciplina de Química, e se podem influenciar na metodologia do professor em relação as concepções do ensino aprendizagem, bem como as diretrizes curriculares da disciplina em questão. Por fim podemos sintetizar que a pergunta geradora da pesquisa é: Qual influência que as metodologias de ensino contidas nos LD de Química disponibilizados pelo PNLD exercem nas aulas do Ensino Médio e como ocorre o processo de escolha e utilização deste recurso didático nas aulas de Química no município de Confresa/MT?

Frente ao problema, tivemos como objetivo de pesquisa identificar os critérios de escolha, a forma de utilização em sala de aula e a avaliação dos professores do Ensino Médio, que atuam em Confresa/MT, sobre os LD de Química. Nessa pesquisa, nem todos os professores participaram da escolha do LD, isso ocorreu devido aos mesmos não fazerem parte do quadro da escola na época da escolha, outros porque estavam em qualificação profissional (mestrado, doutorado).

\section{Reflexões teóricas sobre os Livros Didáticos}

O LD é uma das principais formas de documentação e consulta empregados por professores e alunos. Nessa condição, ele às vezes termina por influenciar o trabalho pedagógico e o cotidiano da sala de aula (Brasil, 2003). Além disso, é importante por seu aspecto político e cultural, na medida em que reproduz os valores da sociedade em relação à sua visão da ciência, da história, da interpretação dos fatos e do próprio processo de transmissão do conhecimento. 
A influência e a importância do LD na prática docente do professor é o tema de grandes discussões no âmbito da educação básica. Segundo Lopes (1992), o LD, utilizado por professores e alunos auxilia no processo de transmissão do conhecimento, apresenta um grande poder de compreensão e sustentação do ensino.

Nas palavras de Gérard e Roegiers (1998, p. 19), o LD é “um instrumento impresso, intencionalmente estruturado para se inscrever num processo de aprendizagem, com o fim de lhe melhorar a eficácia". Entretanto, segundo os autores, sua utilização assume importância diferenciada de acordo com as condições, lugares e situações em que é produzido e utilizado nos diferentes âmbitos escolares.

O primeiro LD ilustrado foi publicado no ano de 1658, em Nuremberg na Alemanha, chamado de Orbis Sensualium Pictus (O mundo invisível das imagens), de Comenius, esse LD foi um precursor das técnicas audiovisuais. Ele foi composto de 151 elementos de figuras, numerados e na forma de se ligar à palavra ao texto correspondente, e apresentava objeto ilustrado (Nali, 2003). Comenius também escreveu Didacta Magna, um livro que trata sobre a didática e aprendiz dos nossos LDs, sendo a disciplina escolar que atrai e obriga todos a observar os ensinamentos (Comênio, 2006).

Referente ao contexto brasileiro, o marco da história política do LD no Brasil se deu em 1929, com criação do Instituo Nacional do Livro, para regular a produção nacional de obras em contraponto aos estrangeiros. Segundo Freitag, Costa e Motta (1989), a definição por essa data se justifica pelo fato de se desenvolver no Brasil uma política educacional consciente, com exigências democráticas, e que permaneceu até a Nova República.

A primeira reforma educacional de caráter nacional, realizada por Francisco Campos (1931-1940), estruturou o ensino secundário, estabelecendo o currículo seriado, a frequência obrigatória e o ensino dividido em dois ciclos. O primeiro correspondia ao fundamental de cinco anos, cujo objetivo era a formação propedêutica com ênfase na cultura humanística, e o segundo, ao complementar de dois anos e visava habilitar o sujeito para o ingresso no Ensino Superior. Para Dallabrida (2009), os destinos políticos educacionais dessas reformas destinavam na formação do cidadão, produção e renovação da elite, que poderiam definir os prosseguimentos da educação.

De acordo com Mortimer (1988), no período correspondente do parágrafo anterior, nessa reforma, os LDs eram influenciados pelos programas educacionais. Como o sistema de ensino 
não previa a organização de disciplinas por séries, os LDs caracterizavam-se como uma coleção de Química geral e não seriado.

Em 2003, foi instituído o Programa Nacional do Livro Didático para o Ensino Médio (PNLEM) por meio da Resolução do FNDE no 38/03 de 23/10/2003. Inicialmente, o programa foi desenvolvido como projeto piloto entre os anos de 2005 e 2007, distribuindo LDs das disciplinas de Língua Portuguesa e Matemática.

No ano de 2007, por meio da Resolução nº 001, o Fundo Nacional de Desenvolvimento da Educação (FNDE) divulgou os princípios e as orientações para avaliação dos LDs de Língua Portuguesa, Matemática, Biologia, História, Química, Física e Geografia. Esses livros foram distribuídos, gradativamente, a alunos das três séries do Ensino Médio de todo o Brasil, prevendo a reutilização por três anos (Brasil, 2020a).

O PNLD é um dos programas do MEC/FNDE. Foi implantado por meio do decreto $n^{\circ}$ 91.542 de 19/08/1985. Seu objetivo é auxiliar o trabalho pedagógico dos professores por meio da distribuição gratuita de LDs aos alunos matriculados nas escolas públicas do Ensino Fundamental e Médio (Brasil, 2020a).

De acordo com Batista (2003), com o intuito de controlar a produção e a circulação do LD no Brasil, em 1938, foi criada a Comissão Nacional do Livro Didático (CNLD). A partir de então, os programas do governo federal para o LD foram aperfeiçoados e ganharam novos formatos até que, no ano de 1985, foi instituído o PNLD, mas ainda com execução diferente da atual.

No ano de 2007 é criado o Programa Nacional do Livro para a Alfabetização de Jovens e Adultos (PNLA) pela Resolução no 18 de 24/04/2007, atendendo alunos jovens e adultos do $1^{\circ}$ ao $9^{\circ}$ ano do Ensino Fundamental, além das entidades parceiras do Programa Brasil Alfabetizado (Brasil, 2020a).

O contexto educacional contemporâneo exige, cada vez mais, professores capazes de suscitar nos alunos experiências pedagógicas significativas, diversificadas e alinhadas com a sociedade em que estão inseridos. Nessa perspectiva, os materiais de ensino, e em particular o LD, têm papel relevante (Brasil, 2005).

Com a finalidade de identificar os critérios utilizados pelos professores de Química na escolha do LD, utilizamos os dados obtidos a partir de um questionário respondido por quinze professores de Química. O objetivo desse estudo era identificar as concepções deles sobre 
características dos LD e os critérios de escolha que utilizavam. Para tanto, o professor necessita possuir determinados saberes, critérios e competências que o tornem apto a realizar, juntamente com seus colegas de trabalho, a escolha do LD (Nuñez et al., 2003).

A questão da qualidade do LD, defendida pelo Ministério da Educação, é bem visível: como garantia da boa escolha pelo professor, o sistema de ensino (representado pelo MEC) realiza uma 'pré-seleção' desse material. Segundo Martins, Sales e Souza (2009, p.16), o resultado pode ser conferido no Guia do Livro Didático (GLD), que contém resenhas de todos os LDs recomendados, agrupadas por áreas do conhecimento.

Como afirma Cassab e Martins (2009), nas escolas públicas, são os professores que escolhem e utilizam o LD como mediador nas aulas, sendo assim, o professor é o principal responsável por organizar esse processo, pois será utilizado nas suas aulas e para o seu planejamento.

Segundo orientações do MEC/FNDE, para realizar a escolha do LD a ser utilizado nos três anos seguintes, os professores e a equipe pedagógica escolar necessitam organizar-se em grupo, em horários adequados destinados para a discussão pedagógica, obedecendo ao cronograma previsto pelo FNDE para realizar a leitura e discussão do GLD. Nesse processo, os profesores precisam considerar o aspecto sociocultural da sua realidade escolar (Brasil, 2020a).

O GLD é resultado de elaborações conjuntas do FNDE, juntamente com professores de instituições de Ensino Superior, que são responsáveis por analisar as coleções inscritas em edital específico, e estes também servem de subsídio ao professor para facilitar a escolha do LD, trazendo as resenhas das coleções aprovadas no processo de avaliação pedagógica. Dessa forma o professor irá realizar a leitura do GLD para identificar a coleção que melhor se adapta à sua metodologia de ensino e à proposta pedagógica da escola.

Os critérios de avaliação do componente curricular Química no PNLD 2015 foram explicitados na ficha de avaliação reproduzida a seguir, que contém 06 blocos de avaliação, sendo: Projeto Editorial; Observância da Legislação brasileira; Abordagem teóricometodológica e proposta didático-pedagógica Correção e atualização de conceitos, informações e procedimentos; Manual do Professor; Análise do conteúdo digital (Brasil, 2014).

Uma das etapas previstas no PNLD consiste na avaliação dos LDs e tem a finalidade de garantir a qualidade do material quanto aos aspectos estrutural e pedagógico. Em seus estudos, Gérard e Roegiers (1998) destacam a avaliação do LD como um processo importante e que 
precisa ser realizado segundo dados que atendam ao processo de elaboração, execução e utilização.

De acordo com Schnetzler (2010), tem se notado que os professores de Ciências/Química geralmente atuam como transmissores mecânicos de conteúdos de LDs, não se envolvendo com práticas inovadoras e repassando aos alunos fatos, informações, conceitos de maneira assistemática e descontextualizada histórica e socialmente.

Relacionado aos elementos do LD, Silveira e Cicillini (2001) apontam que os alunos da educação básica apresentam dificuldade em se posicionar frente aos problemas que exigem conhecimento específico, com relação à disciplina de Ciências, especificamente de Química, essas dificuldades são atribuídas a fatores como: a exposição de muitos conteúdos, a falta de materiais de laboratório e de atividades práticas nas aulas de Química.

\section{Procedimentos Metodológicos}

A pesquisa caracterizou-se como um levantamento, descritivo e exploratório. Segundo Malhotra (2001), as pesquisas podem ser classificadas, em termos amplos, como exploratórias ou conclusivas. As pesquisas conclusivas podem ser divididas em descritivas e causais. Mas segundo Marconi e Lakatos (2003) consideram que existem, basicamente, três tipos de pesquisa cujos objetivos são diferentes: pesquisa exploratória, descritiva e experimental. Apesar de os autores usarem nomes diferentes para os três tipos básicos de pesquisa, elas retratam os mesmos objetivos

Cabe ressaltar que as pesquisas exploratórias têm como objetivo proporcionar maior familiaridade com o problema, com vistas a torná-lo mais explícito ou a constituir hipóteses. Pode-se dizer que estas pesquisas têm como objetivo principal o aprimoramento de ideias ou a descoberta de intuições. Seu planejamento é, portanto, bastante flexível, de modo que possibilite a consideração dos mais variados aspectos relativos ao fato estudado.

A pesquisa exploratória tem por objetivo aprimorar hipóteses, validar instrumentos e proporcionar familiaridade com o campo de estudo. Constitui a primeira etapa de um estudo mais amplo, e é muito utilizada em pesquisas cujo tema foi pouco explorado, podendo ser aplicada em estudos iniciais para se obter uma visão geral acerca de determinados fatos (Gil, 2008). 
De forma semelhante, Gil (1999) considera que a pesquisa exploratória tem como objetivo principal desenvolver, esclarecer e modificar conceitos e ideias, tendo em vista a formulação de problemas mais precisos ou hipóteses pesquisáveis para estudos posteriores. Gil (2008) ainda corrobora que as pesquisas descritivas têm como objetivo primordial descrever as características de determinadas populações ou fenômenos. Uma de suas modalidades está na utilização de técnicas padronizadas de coleta de dados, tais como o questionário e a observação sistemática, analise documental, além das entrevistas.

Godoy (2005) destaca alguns pontos fundamentais para se ter uma "boa" pesquisa qualitativa, tais como: credibilidade, ou seja, apresentar resultados dignos de confiança; transferibilidade, no sentido de realizar uma descrição densa do fenômeno que permita ao leitor imaginar o estudo em outro contexto; confiança em relação ao processo desenvolvido pelo pesquisador; confiabilidade dos resultados, que envolve avaliar se os resultados estão certos com os dados coletados; explicitação cuidadosa da metodologia, detalhando como a pesquisa foi realizada e, por fim, relevância das questões de pesquisa, em relação a estudos anteriores.

A pesquisa foi realizada no segundo semestre de 2019, e investigou as seguintes unidades escolares na área urbana: CEJA Creuslhi de Souza Ramos, instituição especializada na modalidade de Educação de Jovens e Adultos; Escola Tiradentes, escola estadual vinculada a Polícia Militar, que iniciou suas atividades, no município, em 2017; Escola Estadual 29 de Julho que também oferta Ensino Fundamental, Médio e Educação Profissional; Instituto Federal de Mato Grosso (IFMT) Campus Confresa que oferece cursos superiores e médio técnico. Também foram investigados os professores e as seguintes unidades escolares da área rural: Escola Estadual Waldir Bento da Costa; Escola Estadual Antônio Alves Dias; Escola Estadual Santo Antônio; Escola Estadual Sol Nascente; e Escola Estadual Indígena Tapi’Itãwa, que está localizada na terra indígena Urubu Branco.

Escolhemos o questionário como instrumento de coleta de dados. Segundo Gil (1999, p.128), o questionário pode ser definido "como a técnica de investigação composta por um número mais ou menos elevado de questões apresentadas por escrito às pessoas, tendo por objetivo o conhecimento de opiniões, crenças, sentimentos, interesses, expectativas, situações vivenciadas etc.”. Em perspectiva semelhante, Marconi e Lakatos (2003, p. 201) definem questionário como sendo "um instrumento de coleta de dados, constituído por uma série 
ordenada de perguntas, que devem ser respondidas por escrito e sem a presença do entrevistador".

No primeiro momento foi feito um contato com a Assessoria Pedagógica, para que a mesma disponibilizasse os contatos das secretarias das escolas urbanas e rurais, e que por meio desta estaria passando o contato dos professores participantes da pesquisa, e esse contato foi feito via telefone e outros meios de rede social.

O questionário elaborado foi disponibilizado para professores de Química das escolas estaduais e federal, e continham 15 questões, foi possível identificar o perfil do professor de Química atuante nas escolas de Ensino Médio no que diz respeito à sua formação profissional, tempo de serviço, atuação em outras disciplinas entre outros métodos usados para a escolha do LD, em termo de contextualização, temas abordados, atividades experimentais, proposta inovadora entre outras.

A elaboração de um questionário requer a observância de normas precisas, a fim de aumentar sua eficácia e validade. Em sua organização, devem-se levar em conta os tipos, a ordem, os grupos e a formulação das perguntas e também "tudo aquilo que se sabe sobre percepção, estereótipos, mecanismos de defesa, liderança etc." (Augras, 1974, p. 143).

A pesquisa foi iniciada pelo Instituto Federal de Educação, Ciência e Tecnologia de Mato Grosso (IFMT) Campus Confresa, por ter um quadro maior de professores, atuando na disciplina de Química, sendo um total de seis e por ser da Rede Federal de Ensino. Foram marcados os horários disponíveis para as entrevistas, já que lecionavam em horários e turnos diferentes, depois prosseguindo pelas demais escolas estaduais da zona urbana e fazendo contatos com as os professores das escolas da zona rural, para ganhar tempo e agendar as visitas.

Mesmo que o LD possa ser substituído por fontes de pesquisas rápidas e modernas, ele ainda se constitui em uma ferramenta indispensável para o professor. Apesar de sua presença, o LD não se caracteriza como a única forma de recurso, uma vez que, no planejamento da aula, o professor tem autonomia para desenvolver os conteúdos programados com outros recursos.

A metodologia utilizada para interpretar os dados foi a análise de conteúdo. Para Bardin (2012), esse método designa um conjunto de técnicas de análise das comunicações visando a obter, por procedimentos sistemáticos e objetivos de descrição do conteúdo das mensagens, indicadores (quantitativos ou não) que permitam a inferência de conhecimentos relativos às condições de produção/recepção (variáveis inferidas) destas mensagens. A autora indica que a 
utilização da análise de conteúdo prevê três fases fundamentais: pré-análise, exploração do material e tratamento dos resultados: inferência e a interpretação.

A respeito da organização da análise, Bardin (2012) coloca que tendo "à disposição resultados fiéis e significativos, pode o analista propor inferências e adiantar interpretações a propósitos dos objetivos previstos, ou que digam respeito" ao surgimento de resultados inesperados. Diante desses dados, foram observados os critérios de seleção do LD de Química e os possíveis erros conceituais encontrados, os métodos de utilização do mesmo, bem como a forma que utilização em suas aulas.

\section{Resultados e Discussões}

Sobre os critérios de seleção para o LD de Química e possíveis erros, do IFMT, do total de seis professores apenas dois participaram da escolha do LD no ano de 2017, os demais estavam em qualificação profissional e os outros não faziam parte do quadro de funcionário da instituição. Segundo os professores os LDs foram escolhidos com base nas análises criteriosas de cada GLD que submete ao PNLD, observando quantidades de erros, objetividade, atualização e abordagem da Tecnologias da Informação e Comunicação (TICs), após analisado esses itens, foi feito a votação pelos professores. O LD escolhido foi “Química Cidadã” dos autores Wildson Santos e Gerson Mól (coordenadores).

Da Escola 29 de Julho, apesar dos professores não terem participado da escolha do LD, uma delas relatou que em conversa com outros professores, foi feito em assembleia por professores da área, sendo escolhido o LD "Química Cidadã” dos autores Wildson Santos e Gerson Mól (coordenadores).

Referente à Escola Creuslhi a professora também não participou, mas em conversa com os outros professores, a escolha foi feita pela linguagem do livro, do conteúdo de fácil entendimento da modalidade Ceja, sendo escolhido o LD da Coleção Viver Aprender - dos autores Carla Newton Scrivano, Eraldo Rizzo de Oliveira, Julio Cezar Foshini Lisboa e Rubens Gorski.

Da Escola Militar Tiradentes o professor não participou e não informou como foi feita a escolha. O LD que se encontra na unidade escolar é o de Química - de Martha Reis Marques Fonseca, porém o professor informou que não está trabalhando com o mesmo em sala, salientou que ao avaliá-lo não encontrou todos os conceitos necessários para ministrar suas aulas. 
Já da Escola Antônio Alves Dias, o professor participou da escolha do LD, que foi feita pela internet no portal do MEC, com muitas opções, foi escolhido "Química” da autora Martha Reis Marques Fonseca, no ano de 2019.

Da Escola Santo Antônio o professor não participou da escolha e não informou como feita a mesma. O LD que é trabalhado na escola é o "Química Cidadã", dos autores Wildson Santos e Gerson Mól (coordenadores).

Referente à Escola Sol Nascente, o professor participou da escolha, onde foram sugeridos três autores, em votação foi feito a escolha de um autor, sendo escolhido o "Química Cidadã” - dos autores Wildson Santos e Gerson Mól (coordenadores) no ano de 2017.

Da Escola Waldir Bento o professor não participou da escolha e não informou como foi feito. O LD que se encontra na unidade escolar é o de "Química" - de Martha Reis Marques Fonseca, porém o professor informou que não está trabalhando com mesmo nas suas aulas, salientou que ao avaliar o LD disponível na escola, não teve todos os conceitos necessários para ministrar suas aulas.

Considerando a Escola Indígena Tapi’Itãwa, o professor não utiliza o LD de Química, estes ficam guardados na biblioteca, para casual uso em pesquisas relacionadas a disciplina. $\mathrm{O}$ LD utilizado por eles é um LD da cultura local, a escolha desse livro foi elaborada pela liderança indígena, por professores Tapirapé juntamente com a participação da etnia local, o mesmo foi elaborado no ano de 2015.

Com base nos dados mencionados é evidente a limitada preparação de alguns professores para participar dos processos de seleção do LD, tarefa bastante exigente para um coletivo que pouco tem recebido em termos de saberes, competências e habilidades para tal fim (Nuñez et al., 2003).

Sobre os erros encontrados nos LDs, os mais destacados por eles foram a ortografia e os exercícios, pela minoria encontraram erros conceituais e até mesmo de impressão e experimentos, outros foram a pouca abordagem dos conteúdos de base obrigatória da Química, e também poucos conteúdos não preparando com eficiência para ser estudado em sala de aula com base para exames externos.

Sobre os aspectos que adotam ou adotaria na escolha do LD, os resultados estão expressos no Quadro 1. 
Quadro 1 - Critério adotado ou que adotaria para escolher o LD.

\begin{tabular}{|c|c|c|c|c|c|c|c|c|c|c|c|c|c|c|c|}
\hline & \multicolumn{15}{|l|}{ Contextualização } \\
\hline & \multicolumn{15}{|l|}{ Linguagem apropriada } \\
\hline & \multicolumn{15}{|l|}{ Temas abordados } \\
\hline \multicolumn{16}{|c|}{ Exercícios } \\
\hline \multicolumn{16}{|c|}{ Proposta inovadora } \\
\hline \multicolumn{16}{|c|}{ Ativ. Experimentais } \\
\hline \multicolumn{16}{|c|}{ Interdisciplinaridade } \\
\hline \multirow{2}{*}{\multicolumn{16}{|c|}{$\begin{array}{l}\text { Tradição do LD } \\
\text { Outras observações }\end{array}$}} \\
\hline & & & & & & & & & & & & & & & \\
\hline & & \begin{tabular}{l|l}
1 & 2 \\
$r$
\end{tabular} & \begin{tabular}{l|l}
2 & 3 \\
\end{tabular} & 4 & 5 & 6 & 7 & 8 & & 10 & 11 & 12 & 13 & 14 & 15 \\
\hline
\end{tabular}

Fonte: Dados coletados na pesquisa (2019).

Analisando os dados contidos no Quadro 1, notamos que a 'contextualização' foi considerada por todos os professores como essencial na escolha do LD, sendo a ação de estabelecer um contexto para determinado conceito, normalmente com o intuito de explicar os motivos ou características precedentes de uma situação, logo depois a 'linguagem apropriada' sendo essa que apresenta aspectos da fala científica, uma linguagem mais adequada ao nível de aprendizagem.

Os 'temas abordados' sendo um texto que transmite um tema que foi escolhido para debate entre alunos. Pesquisas realizadas por Santos (2006) e Lima e Silva (2010) revelam que os professores consideram importante a abordagem dos conteúdos como critério para a escolha do LD de Química. Segundo os autores, a abordagem dos conteúdos deve estar associada à linguagem utilizada, que necessita ser clara e acessível ao aluno. Delizoicov (1995) defende que o professor precisa estar instrumentalizado para detectar e observar as fragilidades implícitas no $\mathrm{LD}$, bem como em qualquer outro material a ser utilizado em sala de aula.

Dentre esses critérios mencionados para a escolha, foi observado que os professores do IFMT analisaram também as atividades experimentais, devido a instituição ter laboratórios para as devidas análises, em contrapartida está opção não foi escolhida por outras escolas, por não ter esses laboratórios. Quanto a 'tradição do livro' e 'outras observações', notamos que não deram muita consideração, sendo marcado poucas vezes.

Sobre a seleção de conteúdos presentes no $\mathrm{LD}$, verificamos se todos os professores trabalham com todos os conteúdos contidos no LD ou somente selecionam as partes que 
consideram mais importantes. Para preservar a identidade dos professores, os nomes foram substituídos por letras do alfabeto, sendo que cada professor é representado por uma letra. Logo no Quadro 2, temos uma visão geral das respostas.

Quadro 2 - Se trabalham como todos conteúdos presentes no LD.

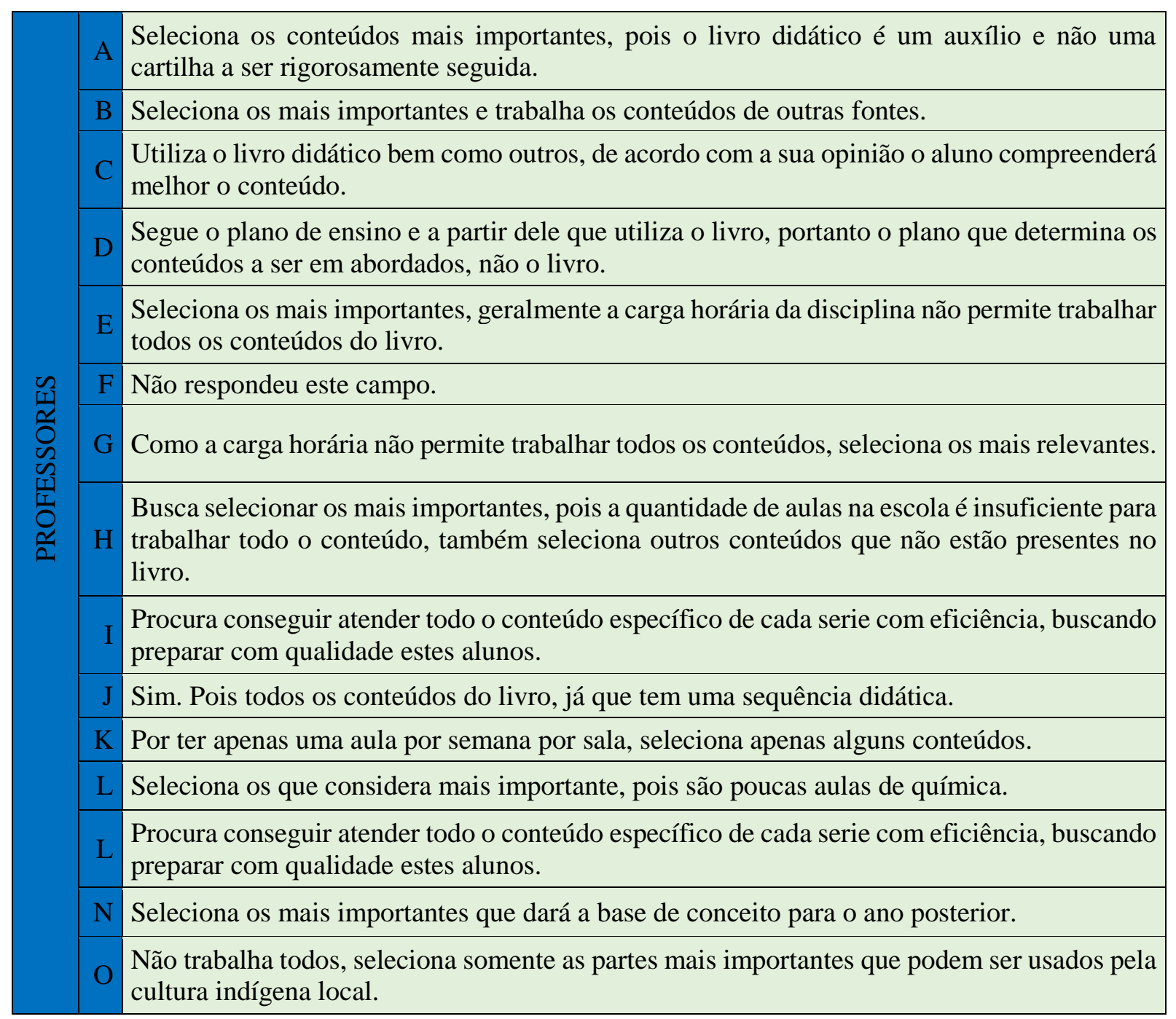

Fonte: Dados coletados na pesquisa (2019).

Analisando as informações do Quadro 2, verificamos que os professores selecionam os conteúdos mais importantes e buscam outras fontes alternativas, pois geralmente a carga horária da disciplina não permite trabalhar todos os conteúdos do livro, sendo assim, o LD é um auxílio, pois segundo o professor A o LD não é uma cartilha a ser rigorosamente seguida, outros seguem os conteúdos abordados no plano de ensino, não somente o LD. Verificamos que os professores I e J procuram trabalhar e atender todo o conteúdo presente no $\mathrm{LD}$, pois os mesmos relatam que já tem uma sequência didática para cada série. 
Já os professores $\mathrm{G}$ e H selecionam os conteúdos mais importantes e buscam trabalhar com outros conteúdos que não estão presentes no LD, pois geralmente a carga horária da disciplina não permite trabalhar todos os conteúdos do livro, em relação a isso, Mendes Sobrinho e Leal (2002) expõem, que além dos LDs de Ciências Naturais, também verificaram que os professores utilizavam outros recursos didáticos além do livro-texto, tais como vídeos educativos, atividade de classe, trabalhos em grupos, pesquisa, síntese de conteúdo.

Pelos dados obtidos, verificamos que os professores selecionam os conteúdos mais importantes e buscam outras fontes alternativas, pois geralmente a carga horária da disciplina não permite trabalhar todos os conteúdos do LD, outros selecionam as partes mais importantes que dará base de conceito para o ano posterior. O professor da escola indígena, seleciona somente as partes mais importantes para o ensino dos alunos da cultura local.

Sobre a forma de utilização do LD nas aulas, identificamos os aspectos gerais do livro na opinião dos professores entrevistados (Quadro 3).

Quadro 3 - Sobre a forma de utilizar o LD em suas aulas.

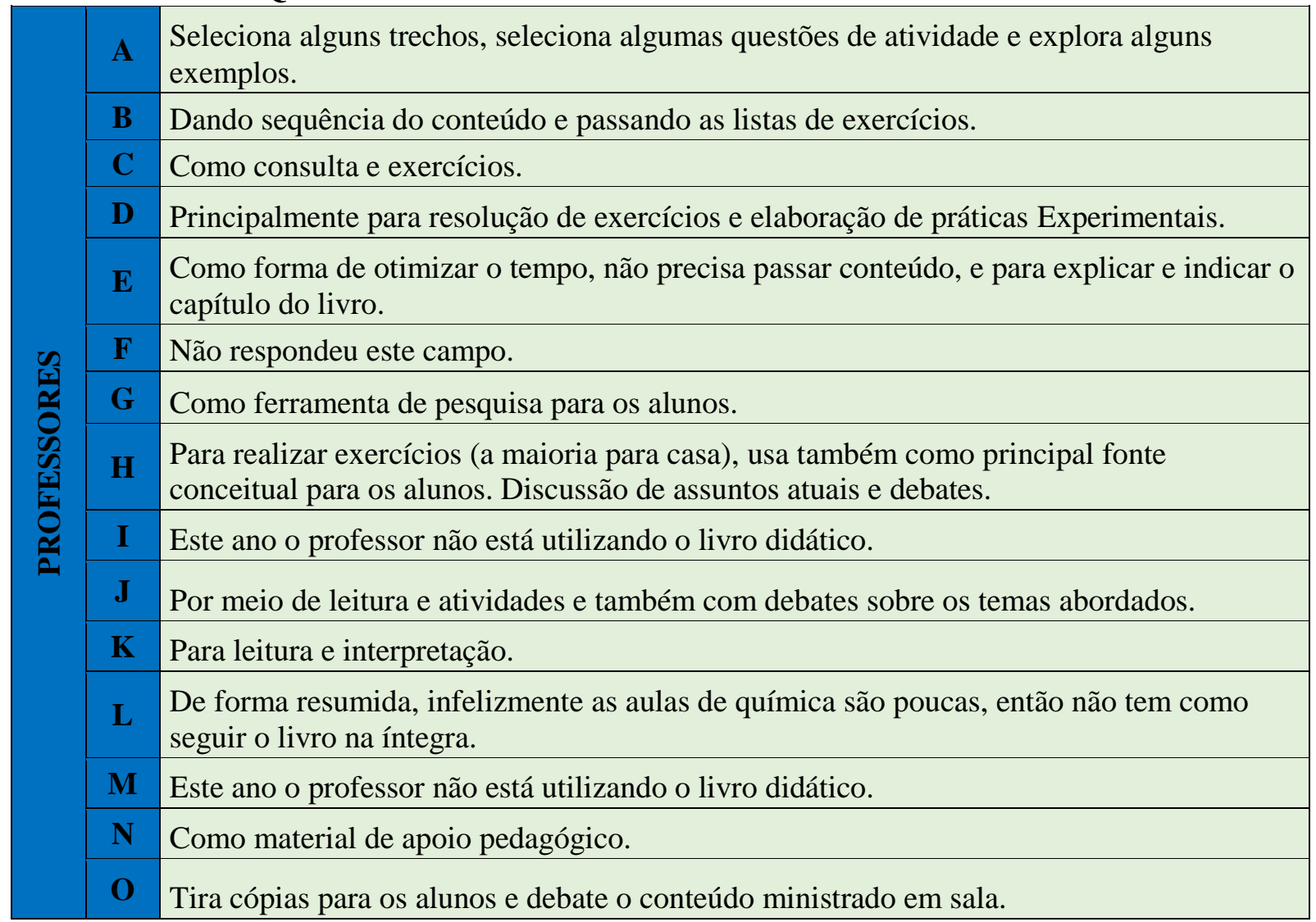

Fonte: Dados coletados na pesquisa (2019). 
Analisando o Quadro 3, notamos que os professores selecionam os trechos mais importantes, utilizam para aplicar atividades, para as práticas experimentais, para leitura, consultas e explicações, também como forma de minimizar o tempo, não precisando passar conteúdo no quadro, assim indicando somente o capítulo do LD para os alunos transcreverem para o caderno.

Os professores M e I não estavam utilizando o LD no ano letivo, pois optou por utilizar outros meios para trabalhar suas aulas, relacionado a isso Chassot (1990, p. 35) diz que: "Mesmo que o professor tenha dificuldades em selecionar assuntos mais ligados ao cotidiano e preferir, por encontrar nisso apoio nos livros- textos, os 'conteúdos clássicos' (aqueles que se disse que são universalmente ensinados), é preciso questionar de uma maneira enfática: o que ensinar sobre determinado assunto?".

Da escola indígena, o professor utiliza o LD de sua cultura tirando cópias para os alunos e debatendo o conteúdo ministrado em sala, já que o exemplar é oferecido somente ao professor. Em curiosidade sobre o conteúdo de Química que trabalham, o mesmo informou que está relacionada a ensinar o que segue a tradição na fabricação de tintas para pintura corporal, mostrando o processo de como é feita a extração das massas das plantas nativas como o jenipapo e urucum, fazendo uma composição química de mistura com o carvão, ensinam também as misturas essenciais das plantas, usando ervas, sementes e hortaliças para alimentação e fermentação no preparo de bebidas e remédios, pelas respostas, notamos que os livros que utilizam tem conteúdos que são diferentes dos LDs habituais, apesar da criação do PNLEM/PNLD, previa que os LD deveriam trazer discussões sobre as diversas culturas/povos.

Em outras palavras, esses alunos foram apresentados para uma nova dimensão da cultura, a ciência/química. Essa nova dimensão da cultura - aprender ciências - "está mais relacionado a entrar num mundo que é ontologicamente e epistemologicamente diferente do mundo cotidiano" (Mortimer, 2000, p. 65).

Ao serem questionados sobre uso do LD como fonte de consulta para elaborar aulas, foram quatro professores que marcaram a opção 'sempre', cinco deles marcaram 'com frequência', outros três marcaram 'intermediária' e em mesma quantidade 'nunca' usam como fonte para elaborar aulas. Os demais não responderam ao questionamento.

Reforçando esse posicionamento, Loguercio, Samrsla e Del Pino (2001) realçam o quanto se tornou importante e indispensável para os professores de Ciências (Química) o uso do 
LD para o estudo e preparação de suas aulas, servindo como um roteiro a ser seguido sem questionamentos.

Nesse sentido, o LD é apresentado como guia curricular, orientador da prática docente, por vezes com maior influência sobre as ações dos professores do que os próprios referenciais curriculares (Lopes, 2005a; Mello, 2004).

Para as opções 'pouco' que não foi selecionada, e 'nunca' que foi selecionada por três professores, Santos e Mol (2005) relatam que os professores não estão habituados a analisar LDs baseados em critérios fundamentados teoricamente e, por vezes, os critérios limitam-se a aspectos como conteúdo, exercícios de vestibulares, alguma alusão ao dia-a-dia dos alunos.

Notamos que o LD era utilizado como material de apoio, de consulta e para planejar as aulas. Apesar de fazer uso de outros materiais, como revistas e textos extraídos da internet e jornais, de modo inconsciente o foco sempre voltava para o LD adotado na escola.

Sobre a frequência de utilização do LD nas aulas, foram quatro professores que marcaram a opção 'sempre', outros quatro marcaram 'com frequência', foram três marcaram 'intermediária', um deles marcou 'pouco' e outros três marcaram que 'nunca' utilizam nas aulas que ministram. Os demais não responderam ao questionamento.

Nesse sentido, Britto (2002) aponta que a diferença na qualidade no ensino não se baseia apenas no LD, mas nas condições em que se dá o processo pedagógico. Dessa forma, mesmo um livro inovador não efetivará a aprendizagem sem uma adequada prática pedagógica. Portanto, o LD sozinho não garante o processo de ensino-aprendizagem, embora norteie o processo.

Sobre a utilização de outro meio didático para a preparação das aulas, as respostas seguem apresentadas no Quadro 4. 
Quadro 4 - Utilização de outro meio didático para preparar aulas.

\begin{tabular}{|c|c|l|}
\hline \multirow{1}{*}{} & A & Sim. Utiliza livros do conteúdo ministrado. \\
\hline B & Sim. Internet, livros diversos. \\
\hline C & $\begin{array}{l}\text { Sim. Livro de Química - Marta Reis, Livro de Química - Feltre; Livro de Química - } \\
\text { Usberco e Salvador. }\end{array}$ \\
\hline D & Sim. Outros livros, websites. \\
\hline E & $\begin{array}{l}\text { Sim. Paradidáticos, artigos da Revista Química Nova na Escola. Plataforma EduCapes, } \\
\text { aplicativos de química, etc. }\end{array}$ \\
\hline F & Não respondeu este campo. \\
\hline G & Sim. Livros, artigos, websites. \\
\hline H & Sim. Química: A ciência Central - Autor Brown; Princípios de Química - Atkins. \\
\hline I & $\begin{array}{l}\text { Sim. Química - Geraldo Camargo de Carvalho; Química Moderna - Marcos Araújo; } \\
\text { Química completa para vestibulares e outros. }\end{array}$ \\
\hline J & Sim. Artigos, apostilas, vídeos e outros. \\
\hline K & Sim. Usa a internet como suporte nas aulas. \\
\hline L & Sim, internet, revistas e artigos, etc. \\
\hline M & $\begin{array}{l}\text { Sim. Química - Geraldo Camargo de Carvalho; Química Moderna - Marcos Araújo; } \\
\text { Química completa para vestibulares e outros. }\end{array}$ \\
\hline N & Sim, websites na internet \\
\hline O & Não, somente o livro da cultura. \\
\hline
\end{tabular}

Fonte: Dados coletados na pesquisa (2019).

Analisando o Quadro 4, notamos que todos os professores usam outros meios didáticos para preparar suas aulas, como livros paradidáticos, artigos, apostilas, revistas e websites relacionado ao conteúdo ministrado.

O professor da escola indígena informou que somente usa o LD da cultura, resumimos então que a educação diferenciada necessita ser elaborada de acordo com cada cultura, ou seja, é necessária a participação dos principais interessados no estudo para elaboração de planos pedagógicos.

Sobre os motivos atribuídos ao fato de alguns alunos não levarem o LD para a escola, as respostas podem ser observadas no Quadro 5. 
Quadro 5 - Quais motivos atribui de alguns alunos não levarem o LD para a escola

\begin{tabular}{|c|c|l|}
\hline A & Falta de compromisso, nem sempre utiliza o livro, pelo peso e volume que ocupa \\
\hline B & Talvez o desinteresse e a falta de lugares adequados para guardar os materiais \\
\hline C & Falta de organização dos alunos, alteração de horários de aulas. \\
\hline D & $\begin{array}{l}\text { Alegam medo de perde-lo, pois o mesmo precisa ser devolvido à escola, alegam o } \\
\text { excesso de peso na mochila. }\end{array}$ \\
\hline E & Excesso de livros e materiais, pouco uso por algumas disciplinas. \\
\hline F & Não respondeu este campo. \\
\hline G & Esquecimento, mudança dos horários das aulas. \\
\hline H & Devido ser usando poucas vezes, sendo mais extraclasse, e também pelo peso. \\
\hline I & Este ano o professor não está utilizando o livro didático. \\
\hline J & $\begin{array}{l}\text { O fato dos livros ficarem na escola para serem usados por todos, então os alunos não } \\
\text { levam para casa. }\end{array}$ \\
\hline K & O professor informou que os alunos sempre levam nas suas aulas. \\
\hline L & Devido à falta de livros para todos os alunos, os livros ficam na escola. \\
\hline M & $\begin{array}{l}\text { Este ano o professor não está utilizando o livro didático, não sendo preciso leva-lo para } \\
\text { casa. }\end{array}$ \\
\hline N & $\begin{array}{l}\text { É que há outros meios de fonte de pesquisa para o aluno que envolve outros conceitos, ou } \\
\text { ouras abordagens. }\end{array}$ \\
\hline $\mathbf{O}$ & $\begin{array}{l}\text { Os alunos não fazem uso do livro didático, porém não é preciso leva-lo de casa para } \\
\text { escola. }\end{array}$ \\
\hline
\end{tabular}
Fonte: Dados coletados na pesquisa (2019).

Analisando o Quadro 5, observamos que as opções respondidas pelos professores estão ligadas ao fato de nem sempre utilizarem o mesmo nas aulas, também pelo excesso de peso na mochila pelos livros de outras disciplinas e por falta de compromisso.

Sobre o peso do livro na mochila, o PNLD tem se preocupado com esta questão. No edital do PNLD de Química de 2012, um dos critérios para aprovação da coleção era de que os LDs fossem seriados. Já no edital de convocação do PNLD 2015, uma das exigências é a inscrição das obras na composição multimídia de LDs e impressos, o que sinaliza a possibilidade de os livros serem disponibilizados nos dois formatos (Brasil, 2020a).

Desvios posturais em crianças e adolescentes ocorrem por diversas razões. Dentre as possíveis, estão: o estirão de crescimento, a má postura, o levantamento de peso excessivo, modelos inadequados de mochilas, má distribuição das disciplinas na grade horária e o sedentarismo (Martinez \& Zacaro, 2007). 
O professor J informou o fato de os LDs ficarem na escola para serem usados por todos, não sendo necessário levar para casa. Os professores M e I não optaram por usar o LD, os mesmos não responderam esta opção. O professor da escola indígena, informou que não faz uso do LD, portanto, não sendo necessário ser entregues aos alunos.

Um questionamento solicitou que os professores avaliassem o LD referente a vários aspectos. Para isso, utilizamos uma escala para atribuir valores entre 1 (Nunca/Insatisfatório) e 5 (Plenamente). As respostas foram tabuladas e seguem apresentadas no Quadro 6 que contém marcações das notas mais frequentes em cada aspecto avaliado.

Quadro 6 - Como os professores avaliam o LD na escala de 1 a 5.

\begin{tabular}{|l|c|c|c|c|c|}
\hline \multirow{2}{*}{\multicolumn{1}{c|}{ TEMAS }} & \multicolumn{5}{c|}{ ESCALA } \\
\cline { 2 - 6 } & $\mathbf{1}$ & $\mathbf{2}$ & $\mathbf{3}$ & $\mathbf{4}$ & $\mathbf{5}$ \\
\hline a) Contextualização & $\mathbf{2}$ & $\mathbf{1}$ & $\mathbf{3}$ & $\mathbf{5}$ & $\mathbf{3}$ \\
\hline b) Linguagem apropriada & $\mathbf{0}$ & $\mathbf{3}$ & $\mathbf{2}$ & $\mathbf{6}$ & $\mathbf{3}$ \\
\hline c) Proposta inovadora & $\mathbf{2}$ & $\mathbf{4}$ & $\mathbf{6}$ & $\mathbf{2}$ & $\mathbf{0}$ \\
\hline d) Temas abordados & $\mathbf{2}$ & $\mathbf{0}$ & $\mathbf{6}$ & $\mathbf{3}$ & $\mathbf{3}$ \\
\hline e) Exercícios & $\mathbf{1}$ & $\mathbf{4}$ & $\mathbf{3}$ & $\mathbf{4}$ & $\mathbf{2}$ \\
\hline f) Interdisciplinaridade & $\mathbf{1}$ & $\mathbf{3}$ & $\mathbf{3}$ & $\mathbf{4}$ & $\mathbf{3}$ \\
\hline g) Tradição do LD & $\mathbf{6}$ & $\mathbf{3}$ & $\mathbf{2}$ & $\mathbf{2}$ & $\mathbf{1}$ \\
\hline h) Atividades Experimentais & $\mathbf{0}$ & $\mathbf{1}$ & $\mathbf{5}$ & $\mathbf{2}$ & $\mathbf{6}$ \\
\hline TOTAL NA ESCALA & 14 & 19 & 30 & 28 & 21 \\
\hline
\end{tabular}

Fonte: Dados coletados na pesquisa (2019).

Analisando o Quadro 6, contendo os temas relacionados ao LD, notamos que avaliaram mais vezes como 3 e 4 na escala. Dos quatorze professores, destacamos a contextualização que foi avaliado por oito deles com nota 4 e 5 na escala, três deles com nota 3, um com 2, e dois com nota 1. A linguagem apropriada também foi destaque sendo avaliado por nove deles com nota 4 e 5, dois com nota 3, e três com nota 2. Segundo Roque e Silva (2008) e Santos e Schnetzler (1996), a aprendizagem da Química se caracteriza pela apropriação de uma linguagem específica que traduz a descrição dos fenômenos.

Observado a qualidade do aprendizado no Ensino de Química, a contextualização tem sido uma das propostas para tornar o estudo mais interessante. Segundo Silva (2011), para que esta proposta tenha resultado, deve-se relacionar, com a Química, aspectos que atendem a 
cidadania, envolvendo a participação do aluno, por meio do debate em sala de aula, objetivando as problematizações do cotidiano.

A contextualização pode ser compreendida como o modo de relacionar conteúdos de ensino e aprendizagem com o cotidiano, com o mundo do trabalho ou com o contexto social, então compreender a contextualização como uma atitude pedagógica de relacionar constantemente conceitos, temas e procedimentos com o cotidiano é tarefa complexa, principalmente num país como o nosso, com grande diversidade e pluralidade social e cultural, em que diferentes juventudes vivem diferentes cotidianos (Brasil, 2014).

Destacamos também as atividades experimentais, que foram avaliados por oito deles com escala 4 e 5 . Notamos que para a escala 5, o LD foi avaliado por boa parte dos professores da Instituto Federal, devido ter laboratórios para as análises das atividades, neste caso, não sendo prioridade para outras escolas que não têm, para tanto que 5 deles avaliaram com escala 3 e um com escala 1.

A inserção de atividades experimentais é útil na disciplina de Química, pois é mais uma ferramenta que ajudará na assimilação dos conteúdos pelos alunos. Reforçando essa ideia, Silvério (2012) aponta que o uso de atividades experimentais é importantíssimo no Ensino de Química. Para o autor, trabalhar com a Química apenas com o livro texto e o quadro negro, sem a presença de atividades experimentais, é como tentar cozinhar sem ter fogo (Silvério, 2012). Observamos a tradição do livro, que foi avaliado por seis professores com escala 1, e apenas por 3 deles com escala 4 e 5, notamos então, que para este parâmetro não foi dada muita importância. Destacamos também os temas abordados, só para escala 3, foi avaliado por seis professores, e por mais seis com escala 4 e 5, notamos então que priorizam também este tema.

O LD está presente no cotidiano das aulas dos professores investigados, constituindo-se no principal recurso. Alguns fatores contribuem para que o LD seja um elemento essencial no meio escolar; dessa forma, as principais ações relacionadas ao seu uso podem ser destacadas na forma como os professores se referem ao LD ao trabalhar os conteúdos, indicando páginas, figuras, trechos que precisam ser copiados e exercícios a serem resolvidos.

Essa constatação corrobora a crítica de Maroja (2007), que defende ser o LD um recurso didático útil no processo educativo, porém nem sempre seu potencial é explorado, principalmente se os professores de Química continuam valorizando os modelos curriculares que evidenciam fórmulas e a memorização. 


\section{Considerações Finais}

Na presente pesquisa foi possível observar quais foram os parâmetros de escolha para o LD. Vimos que os critérios da contextualização, linguagem apropriada e temas abordados foram destaques nas observações destes professores. Destacamos também que os professores do IFMT avaliaram como importante nas suas aulas as atividades experimentais, devido a instituição ter em sua unidade laboratórios para as devidas análises, em contrapartida este quesito não foi bem avaliado como essencial por outras escolas, por motivo das mesmas não possuírem esses laboratórios.

Também foi possível observar o quadro de professores graduados em Química atuando por escola, em especial para o número dos professores do IFMT, sendo um total de seis, apesar de ser uma instituição que oferta o Ensino Médio, comparamos a maioria das outras escolas que conta somente com um professor atuando na disciplina. Todos os profissionais investigados eram habilitados para a tal disciplina, exceto o da escola indígena, sendo graduado em pedagogia intercultural.

Nesse sentido, percebemos a necessidade da formação continuada do professor, para que esse profissional possa ter contato com as várias formas de abordagens no Ensino de Química que valorizem a investigação e problematização dos conteúdos, para que esse profissional possa refletir sobre sua prática.

Acredita-se que embora o LD tenha um papel importante dentro do contexto educacional brasileiro, ele sozinho não obtém êxito nas tarefas de alfabetização e letramento científico e tecnológico necessário para que os alunos desenvolvam habilidades e competências, capacitando-os ao pleno exercício da cidadania. Então cabe ao professor em sua prática pedagógica utilizar outros recursos pedagógicos para potencializar o processo de formação desses alunos.

No que diz respeito à utilização de materiais complementares ao LD, observamos que a maioria dos entrevistados recorre a outro LD para elaborarem suas aulas, tornando evidente a forte influência que o mesmo exerce na prática docente desses profissionais.

Diante dos resultados, esperamos que a pesquisa possa contribuir para a formação de professores de Química que atuam no Ensino Médio, e também servir de subsídio para futuros estudos relacionados à escolha e utilização do LD, e que também possa servir para pesquisas de 
metodologias verificando de que forma foram utilizados pelos professores como métodos de utilização do LD, fonte de pesquisa e de que forma trabalham os conteúdos presentes no LD.

\section{Referências}

Augras, M. (1974). Opinião pública: teoria e pesquisa. $2^{\text {th }}$. Vozes. Petrópolis.

Bardin, L. (2012). Análise de conteúdo. Edições 70. São Paulo.

Batista, A. A. (2003). A avaliação dos livros didáticos: para entender o Programa Nacional do Livro Didático (PNLD). In: Roxane Rojo e Antônio Batista (Org.). Livro didático de Língua Portuguesa, Letramento e Cultura da Escrita. Mercado de Letras. Campinas, SP.

Brasil. (1939). Decreto-Lei $n^{\circ} 1.006$, de 30 de dezembro de 1938. Estabelece as condições de produção, importação e utilização do livro didático. Diário Oficial [da República Federativa do Brasil], Brasília, DF, Seção 1, 05 jan. 1939, p. 277. Disponível em <http://www.lexml.gov.br/urn/urn:lex:br:federal:decreto.lei:1938-12-30;1006>.Acesso em: 22 mar. 2020.

Brasil. (2003). MEC Ministério da Educação. Secretaria de Educação Fundamental. Projeto de avaliação dos livros didáticos da $1^{a}$ à $4^{a}$ série. v. $2^{\text {th }}$. Brasília.

Britto, L. P. L. (2002). Livro didático e autonomia docente. Scripta, Belo Horizonte, 6(11), pp. 162-170.

Cassab, M. \& Martins, I. (2009). A escolha do livro didático em questão. In: Encontro Nacional De Pesquisa Em Educação Em Ciências, 4, 2009, Bauru. Anais... Bauru.

Chassot, A. (1990). A educação no ensino de química. Ijuí: Livraria UNIJUÍ Editora.

Comênio, J. A. (2006). Didática magna. $3^{\text {th }}$. Martins Fontes. São Paulo.

Dallabrida, N. (2009). A reforma Francisco Campos e a modernização nacionalizada do ensino secundário. Educação, 32(2), pp. 185-191, mai. Porto Alegre.

Delizoicov, N. C. (1995). O professor de ciências naturais e o livro didático - no ensino de programas de saúde. 1995. Dissertação (Mestrado em Educação) - Universidade Federal de Santa Catarina, Florianópolis.

Fernandes, E. F. (2009). A política de seleção/adoção do livro didático paras as escolas de Ensino Médio da rede estadual de ensino do município de Itapipoca. 2009. $46 \mathrm{f}$. Trabalho de Conclusão de Curso (Graduação em Ciências Biológicas) - Curso de Ciências Biológicas, Universidade Estadual do Ceará, Itapipoca.

Freitag, B.; Motta, V. R. \& Costa, W. F. (1989). O Livro Didático em Questão. Cortez Autores Associados. São Paulo.

Gérard, F. M.; Roegiers, X. (1998). Conceber e avaliar manuais escolares. Porto. Porto. 
Gil, A. C. (1999). Métodos e técnicas de pesquisa social. $5^{\text {th }}$. Atlas. São Paulo.

Gil, A. C. (2008). Como elaborar projetos de pesquisa. $4^{\text {th }}$. Atlas. São Paulo.

Godoy, A. S. (2005). Refletindo sobre critérios de qualidade da pesquisa qualitativa. Revista Eletrônica de Gestão Organizacional, 3(2), 81-89, mai./ago.

Lopes, A. R. C. (1992). Livros didáticos: Obstáculos ao aprendizado da ciência química I Obstáculos animistas e realistas. Química Nova, 15(3), 254-281.

Laville, C. \& Dionne, J. (1999). A construção do saber: manual de metodologia da pesquisa em ciências humanas. UFMG. Belo Horizonte.

Lima, M. E. C. de C. \& Silva, P. S. (2010). Critérios que professores de química apontam como orientadores da escolha do livro didático. Ensaio, 12(2), pp. 121-135, mai./Ago. Belo Horizonte.

Loguercio, R.Q.; Samrsla, V.E.E. \& Del Pino, J.C. (2001). A dinâmica analisar livros didáticos com os professores de química. Química Nova, 24(4), pp. 557-562.

Lopes, A. C. (2005). O livro didático nas políticas de currículo. In: Pereira, M. Z.; Moura, A. Políticas e práticas curriculares - impasses, tendências e perspectivas. Idéia. João Pessoa.

Lopes, A. R. C. (1990). Livros didáticos: obstáculos ao aprendizado da ciência química. 1990. 303f. Dissertação. (Mestrado em Educação) - Fundação Getúlio Vargas. Rio de Janeiro.

Machado, N. J. (2018). Grupo de Estudos da Educação Básica Pública Brasileira: Dificuldades Aparentes, Desafios Reais. Diagnósticos e Propostas para a Educação Básica Brasileira. Instituto de Estudos Avançados da USP, 2018. Disponível em: http://www.iea.usp.br/publicacoes/textos/diagnosticos-e-propostas-para-a-educacaobasica-brasileira Acesso em 25 jan. 2020.

Malhotra, N. (2001). Pesquisa de marketing. $3^{\text {th }}$. Porto Alegre: Bookman.

Marconi, M. de A. \& Lakatos, E. M. (2003). Fundamentos de metodologia científica. $5^{\text {th }}$. São Paulo: Atlas.

Martinez, M. A. F. \& Zácaro, P.M.D. (2007). Desvios posturais devido à sobrecarga de mochila. Anais do XI Encontro Latino Americano de Iniciação Científica e VII Encontro Latino Americano de Pós-Graduação. São José dos Campos / São Paulo.

Martins, E. de F.; Sales, N. A. de O. \& Souza, C. A. (2009). O Estado, o Mercado Editorial e o Professor no Processo de Seleção dos Livros Didáticos. Estudos em Avaliação Educacional, 20(42), pp. 11-26, jan. /abr. São Paulo.

Maroja, C. (2007). O Currículo de Química nas Escolas Públicas de Ensino Médio da Cidade de São Paulo. 219f. Dissertação (Mestrado em Ensino de Ciências e Matemática) Universidade Cruzeiro do Sul, São Paulo. 
Mello, J. D. de. (2004). O livro didático como currículo escrito. Anais do VI Colóquio sobre questões curriculares / I Colóquio luso-brasileiro. v. $1^{\text {th }}, \mathrm{CD}-\mathrm{ROM}$.

Mendes Sobrinho, J. A. C. \& Leal, L. M. (2002). O Livro Didático de Ciências Naturais: Influências na Prática Pedagógica. In: II Encontro de Pesquisa em Educação da UFPI, Teresina.

Ministério da Educação. (2005). Secretaria de Educação Básica. Edital de convocação para inscrição no processo de seleção de material didático da língua espanhola para professores do Ensino Médio. Brasília: MEC/SEB/FNDE.

Ministério da Educação. (2013). Fundo Nacional de Desenvolvimento da Educação. Programa Nacional do Livro Didático: legislações. Brasília: FUNDEB. Disponível em: <http://www.fnde.gov.br/programas/livro-didático>. Acesso em: 20 mar. 2020.

Ministério da Educação. (2014). Secretaria de Educação Básica. Guia de livros didáticos: PNLD 2015: Química: Ensino Médio. Brasília.

Mortimer, E. F. (1988). A evolução dos livros didáticos de química destinados ao ensino secundário. Em aberto, 7(40), pp. 25-41, out. /dez. Brasília.

Mortimer, E. F. (2000). Linguagem e formação de conceitos no ensino de ciências. Ed. UFMG. Belo Horizonte.

Nali, M. A. G. (2003). Considerações sobre o conceito de "Natureza" em Comenius. Semina: Ciências Sociais e Humanas, 24(1), pp. 75-86, set. Londrina.

Nuñez, I. B.; Ramalho, B. L.; Silva, I. K. P. \& Campos, A.P.N. (2003). A seleção dos livros didáticos: um saber necessário ao professor. O caso do ensino de ciências. Revista Ibero americana de Educación.

Peruzzo, T. M. \& Canto, E. L. (1999). Química-Coleção Base. Moderna. São Paulo.

Ramalho, B. L.; Nuñez, I. B. \& Gauthier, C. (2000). Quando o desafio é mobilizar o pensamento pedagógico do professor: uma experiência centrada na formação continuada. http://www.anped.org.br

Richardson, R. J. (1999). Pesquisa social: métodos e técnicas. $3^{\text {th }}$. Atlas. São Paulo.

Roque, N. F. \& Silva, J. L. P. B. (2008). A linguagem química e o ensino de química orgânica. Química Nova, 31(4), pp. 921-923. São Paulo.

Santos, B. S. (1998). Introdução a uma Ciência Pós-Moderna. Edições Afrontamento. Porto.

Santos, S. M. O. (2006). Critérios para avaliação de livros didáticos de química para o Ensino Médio. 2006. 235 f. Dissertação (Mestrado Profissionalizante em Ensino de Ciências) Universidade de Brasília, Brasília.

Santos, S. M. O. \& Mol, G. S. (2005). Critérios de avaliação de livros didáticos de Química 
para o Ensino Médio. In: Atas do V Encontro Nacional de Pesquisa em Educação em Ciências, Bauru.

Santos, W. L. P \& Schnetzler, R. P. (1996). Função social: o que significa ensino de química para formar cidadão? Química Nova na Escola, 2(4), pp. 28-34, nov. São Paulo.

Schnetzler, R. P. (2010). Educação em Química: Compromisso com a cidadania. $4^{\text {th }}$. Unijuí. Ijuí.

Silva, A. M. (2011). Proposta para Tornar o Ensino de Química mais atraente. Revista de Química Industrial, 7(31), pp. 7-12.

Silveira, H. E. \& Cicillini, G. A. (2001). O conhecimento químico em apostilas do ensino Fundamental. Ensino em Revista, 9(1), pp. 135-156, jul. /jun. Uberlândia.

Silvério, J. (2012). Atividades experimentais em sala de aula para o ensino de química: percepção dos alunos e professor. 2012. 50f. Trabalho de Conclusão de Curso (Bacharelado e Licenciatura em Química) -Universidade Tecnológica Federal do Paraná. Pato Branco.

Antônio Carlos Barros Resplande. Instituto Federal de Mato Grosso (IFMT) Campus Confresa; Mato Grosso, Brasil. Especialização em Ensino de Ciências pelo IFMT Campus Confresa. Graduação em Licenciatura em Ciências da Natureza com Habilitação em Química pelo IFMT Campus Confresa. Professor da Escola Municipal Vida Esperança (Confresa/MT).

Marcelo Franco Leão. Instituto Federal de Mato Grosso (IFMT) Campus Confresa; Mato Grosso, Brasil. Doutorado em Educação em Ciências pela Universidade Federal do Rio Grande do Sul (UFRGS). Mestre em Ensino pela Universidade do Vale do Taquari (UNIVATES). Especialização em Orientação Educacional pela Faculdade Dom Alberto e em Relações Raciais na Educação e na Sociedade Brasileira pela Universidade Federal de Mato Grosso (UFMT). Graduação em Licenciatura em Química pela Universidade de Santa Cruz do Sul (UNISC) e em Física pela Universidade do Estado de Mato Grosso (UNEMAT). Professor do Departamento de Ensino do IFMT Campus Confresa. Docente permanente do PPG Ensino (IFMT/UNIC). Membro do Grupo de Pesquisa Ensino de

Ciências e Matemática no Baixo Araguaia (EnCiMa).

\section{Como citar o artigo:}

RESPLANDE, A. C. B; LEÃO, M. F. Avaliação, critérios de escolha e utilização dos livros didáticos de química: com a palavra os professores de Confresa/MT. Revista Paradigma Vol. XLII, Nro. 2, Diciembre de 2021 / $01-26$.

DOI: https://doi.org/10.37618/PARADIGMA.1011-2251.2021.p01-26.id1034 